\title{
Effects of supplemental oxygen on cardiac rhythm during upper gastrointestinal endoscopy: a randomised controlled double blind trial
}

\author{
T E Bowling, C L Hadjiminas, R J Polson, J H Baron, R A Foale
}

\begin{abstract}
To investigate the effects of supplemental oxygen on cardiac rhythm during gastroscopy, 103 patients aged over 60 were randomised to receive either supplemental oxygen or air at 2 litres/minute during the procedure. Pulse rate, blood pressure, oxygen saturation, and a Holter cardiac trace were monitored before, during, and for one hour after the gastroscopy. A wide range of electrocardiographic abnormalities were recorded in both oxygen and air groups, of which ventricular and supraventricular ectopic beats were the most common. There were no significant differences in the rate of occurrence of any clinically important cardiac abnormality either between the oxygen and air groups or between the three monitored periods before, during, and after gastroscopy. There were significantly fewer patients, however, with supraventricular extra systoles when oxygen was given during gastroscopy $(\mathbf{p}<0.05)$. Although supplemental oxygen during gastroscopy significantly improved oxygen saturation $(p<0.001 ; 95 \%$ confidence intervals for the difference between the means: 2.9 to $4 \cdot 7$ ), there was no correlation between oxygen saturation and any electrocardiographic changes. It is concluded that electrocardiographic abnormalities are common in patients over 60 , but this study found no evidence that they are induced by gastroscopy. Supplemental oxygen increases oxygen saturation but does not reduce the incidence of clinically important cardiac arrhythmias.

(Gut 1993; 34: 1492-1497)
\end{abstract}

Upper gastrointestinal endoscopy is a comparatively safe procedure with a mortality of 1-6 in 20000 examinations, and an incidence of serious complications of about 1 in $1000 .{ }^{12}$ Over half the morbidity and mortality is due to cardiopulmonary complications, arrhythmias being the most important. ${ }^{1-3}$ The reported incidence of arrhythmias during endoscopy varies from $3 \cdot 5 \%$ to $72 \%,{ }^{+14}$ with hypoxia proposed as an important factor in inducing arrhythmias. ${ }^{15-17}$ It is well established that hypoxia occurs during endoscopic procedures and that oxygen given during upper gastrointestinal endoscopy and endoscopic retrograde cholangiopancreatography (ERCP) will significantly diminish the degree of oxygen desaturation. ${ }^{18-20}$ There has not, however, been adequate assessment of whether improving the oxygen saturation reduces the incidence of arrhythmias. The aim of this study was to investigate the effects of supplemental oxygen both during and after upper gastrointestinal endoscopy.

\section{Subjects and methods}

All patients aged over 60 years having routine upper gastrointestinal endoscopy were eligible for entry into this study. Those having emergency gastroscopy were excluded. Whenever the monitoring equipment was available patients were asked to participate in the study. One hundred and three patients were enrolled with no refusals. They were divided by random numbers into two groups, one receiving oxygen during gastroscopy and the other receiving air. Written informed consent was obtained from each patient before entry into the study, which was approved by the Parkside Health Authority Ethics Committee.

Before the procedure demographic details were obtained from the patient of age and sex, relevant cardiopulmonary history, shortness of breath according to the New York Heart Association criteria, current treatment, and history of smoking. The indication for endoscopy was noted as well as the dose of sedation, the size of endoscope, and length of procedure.

A 'Superlite' Holter monitor (MortaraCardiodata, USA) was connected about 30 minutes before gastroscopy and the cardiac recording commenced. Five minutes before the procedure a pulse oximeter (Model 7840, Konitron instruments, UK) was attached to the right index finger, and a blood pressure cuff for automated readings (Dinamap 1846SX, Critikon, UK) to the right arm. Baseline measurements of blood pressure and oxygen saturation were recorded on two occasions two minutes apart.

On arrival in the endoscopy suite nasal cannulas were attached and, according to the randomisation, either oxygen or air at 2 litres/ minute was given. The oxygen and air cylinders were covered and a three way tap attached to the nasal cannulas. An endoscopy nurse turned on the appropriate cylinder and hence kept the study blinded for the endoscopist, the research nurse, and the patient.

After two minutes a local anaesthetic spray (2\% lignocaine $100 \mathrm{mg}$; Astra Pharmaceuticals, UK) was applied to the back of the throat and intravenous midazolam given to produce a similar level of sedation (usually $2 \cdot 5-5 \mathrm{mg}$ ). At the start of intubation and at extubation a marker button on the Holter monitor was pressed to show accurately the beginning and end of the gastroscopy. The ease of intubation was graded by the research nurse $(\mathrm{CH})$ on a scale of one 
(effortless) to four (traumatic). During the procedure pulse rate, blood pressure, and oxygen saturation were recorded every minute by the research nurse.

At extubation the oxygen/air was switched off and the pulse rate, blood pressure, and oxygen saturation were subsequently recorded every 10 minutes for one hour. The Holter recording was then stopped, and the tapes sent for analysis using the Cardiodata computerised analyser by cardiology technicians unaware of the proceedings in the endoscopy unit. The number per minute of supraventricular and ventricular extrasystoles allowed comparisons to be made between the pre, per, and postendoscopy periods.

Isolated ventricular extrasystoles are frequently found in normal healthy adults, and occur in $1-4 \%$ of standard 12 lead recordings, ${ }^{21}{ }^{22}$ and $39-67 \%$ of 24 hour ambulatory studies. ${ }^{2324}$ Ventricular extrasystoles may occur more commonly in patients with ischaemic heart disease, and their presence may have more sinister implications. ${ }^{25}$ Lown and Wolf classified ventricular extrasystoles occurring at a rate of less than one per minute as isolated and of little prognostic significance, whereas those occurring at a rate of more than one per minute were more indicative of an unfavourable prognosis. ${ }^{26}$ Supraventricular extrasystoles, on the other hand, occur with increasing frequency throughout life, but there is no evidence of an association with ischaemic heart disease or that their presence is of prognostic importance. ${ }^{27-29}$ Other electrocardiographic abnormalities, in addition to ventricular extrasystoles occurring at a rate of more than $1 / \mathrm{min}$, regarded as of 'sinister' importance - that is, markers of potentially serious complications are, ST segment increase or depression of more than $1 \mathrm{~mm}$, supraventricular tachycardia (three or more consecutive supraventricular extrasystoles at a rate of more than 130/min), second or third degree heart block, ventricular bigemini or trigemini, ventricular tachycardia, ventricular fibrillation or asystole. ${ }^{26}$

With reference to the available published works, ${ }^{4-14}$ it was assumed that 'sinister' electrocardiographic abnormalities, as defined above, would occur in $20 \%$ of patients, and that supplemental oxygen administration would decrease this figure to $10 \%$. On this basis to achieve a significant result at the $5 \%$ value with a power of $90 \% 400$ patients would be required. On preliminary analysis of the first 100 Holter cardiac tapes, however, it was apparent that the incidence of these sinister abnormalities was similar between the patients receiving oxygen and those receiving air. Assuming similar proportions even a study of 5000 patients would not have shown a significant difference between the two groups. The study was therefore terminated at this stage.

\section{STATISTICAL ANALYSIS}

The primary analysis was planned to be a comparison of the numbers of subjects in the oxygen and air treated groups with arrhythmias using the $\chi^{2}$ test. The Mann-Whitney $\mathrm{U}$ test was used to assess the significance of any difference between the groups in the frequency of those with arrhythmias. Secondary analyses were to include within group comparisons of arrhythmias, oxygen saturation, pulse rate, and blood pressure between the pre, per, and postgastroscopy periods, using the Wilcoxon matched pairs signed ranks test for the frequency of arrhythmias, and the Students $t$ test for the remaining normally distributed data. Spearman's rank correlation was used to look for any relation between oxygen saturation and incidence of arrhythmias. Finally differences in oxygen saturation, pulse, and blood pressure between the two groups were assessed with the MannWhitney U test. Possible confounding patient variables, such as age, cardiopulmonary history, smoking, and variations in the endoscopic procedure were compared between the two groups using the $\chi^{2}$ test for categorical variables and the Mann-Whitney U test for continuous variables.

\section{Results}

Between November 1990 and June 1991103 patients were studied. The two groups, receiving either oxygen or air, showed similar baseline characteristics (Table I).

Supplemental oxygen at two litres per minute resulted in significantly higher oxygen saturation values during upper gastrointestinal endoscopy (Fig 1). In the group receiving oxygen there was a mean saturation of $95.4 \%$ before gastroscopy

TABLE I Patient and endoscopy details

\begin{tabular}{|c|c|c|}
\hline & $\begin{array}{l}\text { Oxygen } \\
(n=50)\end{array}$ & $\underset{(n=53)}{\operatorname{Air}}$ \\
\hline \multicolumn{3}{|l|}{ Sex: } \\
\hline Male & 26 & 32 \\
\hline Female & & \\
\hline Age: median (range) & $70 \cdot 2(60-89)$ & $71 \cdot 2(60-85)$ \\
\hline \multicolumn{3}{|l|}{ Indications for gastroscopy: } \\
\hline Epigastric pain/dyspepsia & 24 & 26 \\
\hline Check peptic ulcer & 4 & 6 \\
\hline Anaemia & 2 & 6 \\
\hline Nausea/vomiting & 5 & 3 \\
\hline Dysphagia & 4 & 3 \\
\hline Heartburn/reflux & 4 & 2 \\
\hline Varices & 3 & 3 \\
\hline Others & 4 & 4 \\
\hline \multicolumn{3}{|l|}{ Cardiac history: } \\
\hline IHD & 9 & 16 \\
\hline No IHD & 41 & 37 \\
\hline \multicolumn{3}{|l|}{ Respiratory history: } \\
\hline COAD & 3 & 4 \\
\hline Other & 2 & 0 \\
\hline None & 45 & 49 \\
\hline \multicolumn{3}{|l|}{ Shortness of breath ${ }^{\star}$ : } \\
\hline 1 & 13 & 10 \\
\hline 2 & 12 & 14 \\
\hline 3 & 18 & 21 \\
\hline 4 & 7 & 8 \\
\hline \multicolumn{3}{|l|}{ Smoking: } \\
\hline Yes & 14 & 12 \\
\hline No & 36 & 41 \\
\hline \multicolumn{3}{|l|}{ Ease of intubation: } \\
\hline 1 & 21 & 19 \\
\hline 2 & 23 & 23 \\
\hline 3 & 5 & 9 \\
\hline 4 & 1 & 2 \\
\hline \multicolumn{3}{|l|}{ Diameter of endoscope: } \\
\hline $9 \mathrm{~mm}$ & 3 & 4 \\
\hline $11.3 \mathrm{~mm}$ & 47 & 49 \\
\hline \multicolumn{3}{|l|}{ Sedation (midazolam mg): } \\
\hline 0 & 3 & 1 \\
\hline $2 \cdot 5$ & 23 & 24 \\
\hline $5 \cdot 0$ & 24 & 25 \\
\hline $7 \cdot 5$ & 0 & 3 \\
\hline \multirow{2}{*}{$\begin{array}{l}\text { Length of procedure: median [min] } \\
\text { (range) }\end{array}$} & & \\
\hline & $6 \cdot 9(2-19)$ & $7 \cdot 2(2-35)$ \\
\hline
\end{tabular}

^New York Heart Association Criteria, IHD=ischemic heart disease, $\mathrm{COAD}=$ chronic obstructive airway disease. 
Figure 1: Oxygen saturation increased during endoscopy in the oxygen group, and fell afterwards to values significantly below baseline. Oxygen saturation decreased during endoscopy in the air group, and remained unchanged afterwards. Between group comparison showed a significantly higher oxygen during the procedure, but similar values before and after. Each point represents the mean oxygen saturation in an individual patient within each period of monitoring. The horizontal thick line represents the mean.

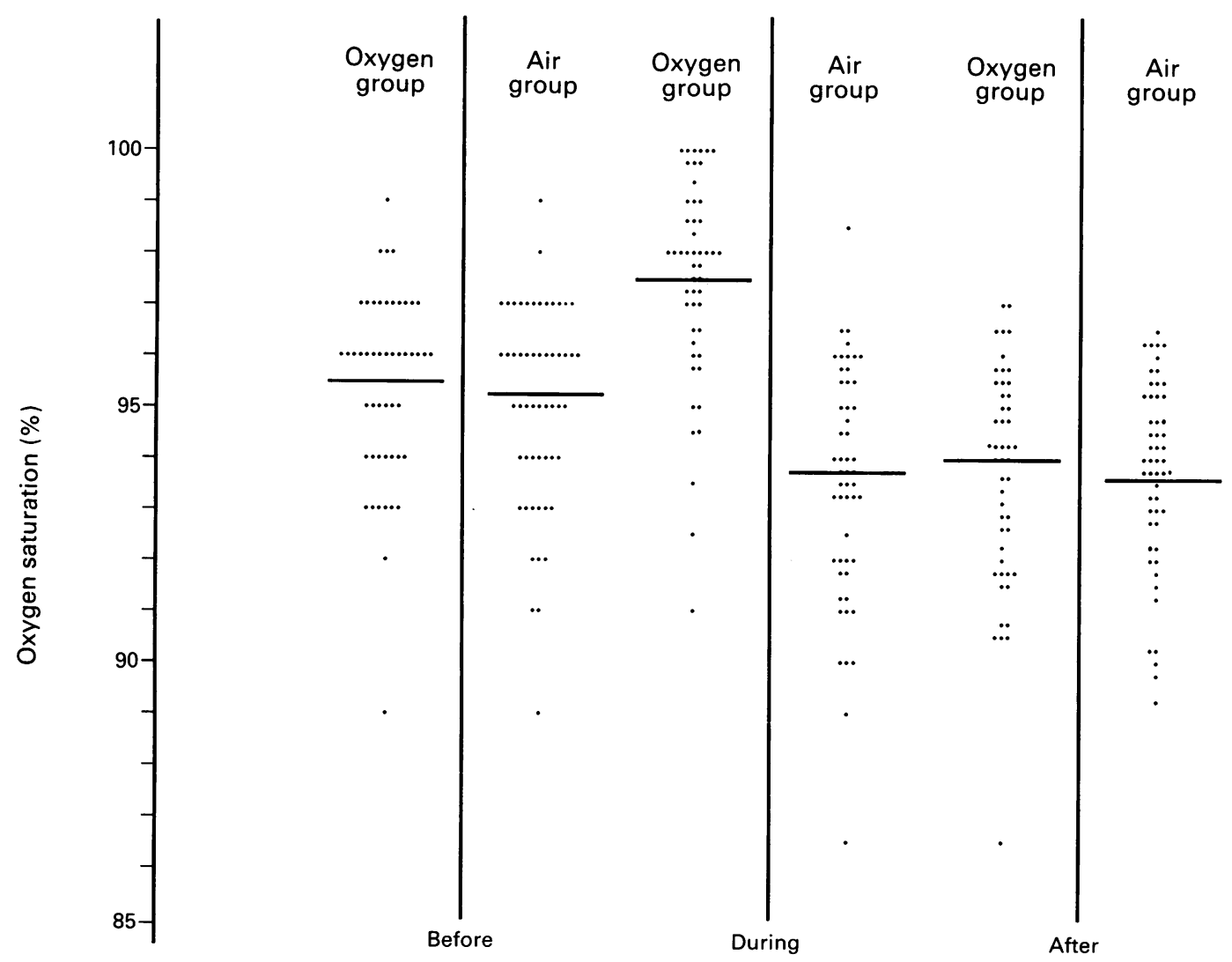

Period of monitoring in relation to gastroscopy

and $97.5 \%$ during the procedure when the oxygen was being given - this represents a significant increase $(p<0.001 ; 95 \%$ confidence intervals (CIs) for the difference between the means: 1.47 to $2 \cdot 73$ ). In the group receiving air the mean saturation was $95 \cdot 2 \%$ before and $93 \cdot 7 \%$ during the gastroscopy - this represents a significant decrease $(\mathrm{p}<0.001 ; 95 \%$ CIs: -0.63 to $-2 \cdot 03)$. The saturation during gastroscopy in the group receiving oxygen was significantly higher than in the group receiving air $(p<0.001$; 95\% CIs: 2.94 to $4 \cdot 68$ ). After the procedure saturation fell to values significantly below baseline in both groups $(\mathrm{p}<0.01 ; 95 \%$ CIs: 2.4 to $3 \cdot 5)$. The lowest oxygen saturation recorded throughout the study was $86 \%$.

Most of the electrocardiographic abnormalities recorded were supraventricular and ventricular extrasystoles (Table II). There were significantly fewer patients with supraventricular extrasystoles when oxygen was given during gastroscopy compared with those receiving air - 15 $(30 \%)$ and $26(49 \%)$ respectively $\left(\chi^{2}=5 \cdot 05\right.$; $0.01<\mathrm{p}<0.05)$. The frequency of these extrasystoles, however, when they did occur, on an extrasystole per minute basis was similar both between the oxygen and air groups and between the three monitored periods before, during, and after the gastroscopy (Fig 2). The number of patients with ventricular extrasystoles of either an 'isolated' (rate less than $1 / \mathrm{min}$ ) or 'frequent' (rate more than $1 / \mathrm{min}$ ) nature was similar in both groups throughout the study (Fig 3).

Although some ST segment changes were

TABLE II Electrocardiographic and haemodynamic measurements

\begin{tabular}{|c|c|c|c|c|c|c|}
\hline & \multicolumn{3}{|c|}{ Oxygen $(n=50)$} & \multicolumn{3}{|l|}{$\operatorname{Air}(n=53)$} \\
\hline & Pre & Per & Post & Pre & Per & Post \\
\hline $\begin{array}{l}\text { Supraventricular extrasystoles (no of } \\
\text { patients) }\end{array}$ & 30 & 15 & 28 & 37 & 26 & 37 \\
\hline $\begin{array}{l}\text { Ventricular extrasystoles (no of patients) } \\
\text { ST segment change (no of patients) } \\
\text { 'Sinister' arrhythmias (no of patients) } \\
\text { Normal trace (no of patients) } \\
\text { Normal trace throughout study (no of } \\
\text { patients) }\end{array}$ & $\begin{array}{r}23 \\
2 \\
10 \\
6\end{array}$ & $\begin{array}{r}12 \\
0 \\
11 \\
16 \\
6\end{array}$ & $\begin{array}{r}22 \\
6 \\
13 \\
5\end{array}$ & $\begin{array}{r}25 \\
6 \\
16 \\
3\end{array}$ & $\begin{array}{r}20 \\
2 \\
11 \\
12 \\
3\end{array}$ & $\begin{array}{r}26 \\
8 \\
17 \\
4\end{array}$ \\
\hline Pulse (beats per minute): median (range) & 74 & $83^{\star}$ & 72 & 78 & $87^{\star}$ & 74 \\
\hline $\begin{array}{l}\text { Systolic blood pressure }(\mathrm{mm} \mathrm{Hg}) \text { : median } \\
\text { (range) } \\
\text { Diastolic blood pressure }(\mathrm{mm} \mathrm{Hg}) \text { : median } \\
\quad \text { (range) } \\
\text { Oxygen saturation } \$(\%) \text { : mean (range) }\end{array}$ & $\begin{array}{l}130 \\
(100-190) \\
60 \\
(40-110) \\
95 \cdot 4 \\
(89-99)\end{array}$ & $\begin{array}{l}151 \dagger \\
(88-208) \\
78 \ddagger \\
(55-120) \\
97 \cdot 5 \\
(89-99)\end{array}$ & $\begin{array}{l}120 \\
(90-150) \\
60 \\
(40-80) \\
93 \cdot 7 \\
(91-100)\end{array}$ & $\begin{array}{l}140 \\
(100-200) \\
60 \\
(40-90) \\
95 \cdot 2 \\
(86 \cdot 7-98)\end{array}$ & $\begin{array}{l}153 \\
(80-217) \\
80 \ddagger \\
(43-112) \\
93 \cdot 7 \\
(86 \cdot 5-97)\end{array}$ & $\begin{array}{l}120 \\
(92-170) \\
60 \\
(40-85) \\
93 \cdot 6 \\
(89 \cdot 7-96)\end{array}$ \\
\hline
\end{tabular}

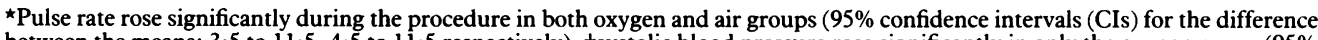
between the means: 3.5 to $11 \cdot 5,4.5$ to 11.5 respectively), tsystolic blood pressure rose significantly in only the oxygen group ( $95 \%$ CIs for the difference between the mean: 8.5 to 23.5 ), $\ddagger$ diastolic blood pressure rose significantly in both oxygen and air groups ( $95 \%$ CIs for the difference between the means: 7 to 21 and 6 to 23 respectively), \&see Figurel for details. 
Figure 2: More patients had supraventricular extrasystoles during endoscopy in the air group. All other statistical analyses between the groups and the pre, per, and post endoscopy periods were not significant. Each point represents the mean number of supraventricular extrasystoles per minute in an individual patient within each period of monitoring.
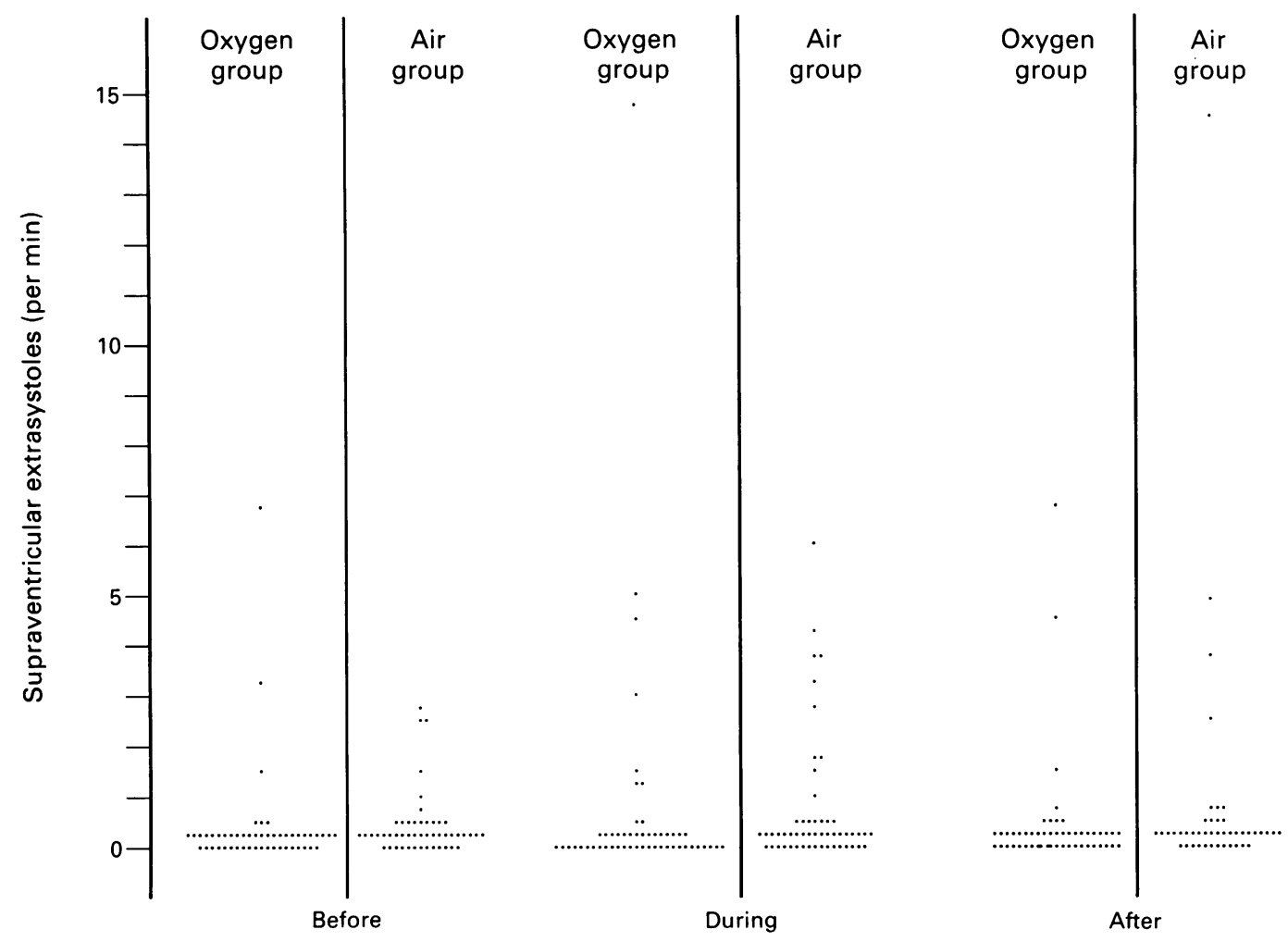

Period of monitoring in relation to gastroscopy

recorded, these occurred equally within the two groups. Of note, 16 of 23 patients with these changes denied any history of ischaemic heart disease. Other changes seen were short runs of supraventricular tachycardia (oxygen group 9; air group 3); sinus bradycardia (oxygen group 2; air group 4), axis change (oxygen group 2; air group 1); ventricular bigemini (oxygen group 1; air group 5) and trigemini (oxygen group 3; air group 2); and several cases of atrial fibrillation (oxygen group 2; air group 3), first degree heart block (oxygen group 1; air group 2), and right bundle branch block (oxygen group 1; air group 2 ) occurring throughout the monitoring. There were no significant differences in any of these arrhythmias between the two groups. Combining all the 'sinister' abnormalities (as defined earlier) there were no significant differences
Figure 3: No significant differences in the number of patients with ventricular extrasystoles between the oxygen and air groups, or between the pre, per, or post endoscopy periods. Each point represents the mean number of ventricular extrasystoles per minute in an individual patient within each period of monitoring.

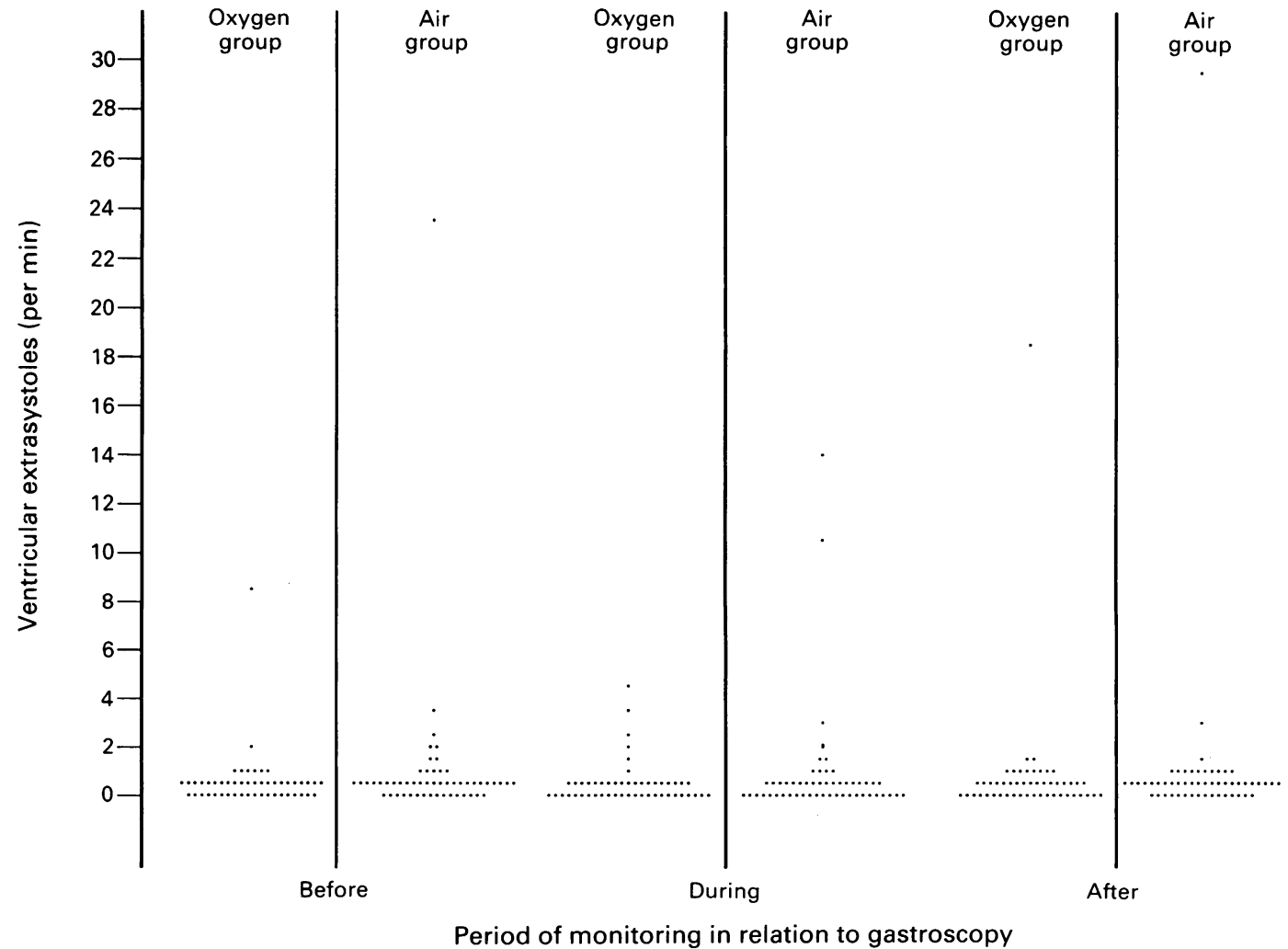


between the oxygen and air groups at any stage of the study (Table II).

Only six patients in the oxygen group and three in the air group showed no electrocardiographic abnormalities at any stage. In both groups more patients had a normal cardiac trace during the procedure than before or after gastroscopy. This probably reflects the shorter period of monitoring rather than any protective effect of the gastroscopy on cardiac rhythm (Table II).

A relative tachycardia was seen during the procedure in many patients, and seemed to be a normal physiological response to the gastroscopy. The pulse rate subsequently fell to baseline values after gastroscopy in both the oxygen and air groups. Similarly the blood pressure rose during the procedure and fell to below baseline immediately afterwards, returning to baseline values by the end of the monitoring period. The rise in blood pressure in the oxygen group was significantly greater than in the air group (Table II).

There was no significant correlation between the frequency of extrasystoles, either supraventricular or ventricular, and oxygen saturation values. There was no significant relation between cardiac arrhythmias or ST segment change and age, sex, shortness of breath (New York Heart Association criteria), or cardiac history.

\section{Discussion}

During gastrointestinal endoscopy hypoxia is well recorded, with many different causal factors. ${ }^{30-35}$ This study shows that supplemental oxygen improves oxygen saturation values during upper gastrointestinal endoscopy, which is in keeping with previous studies of both gastroscopy and ERCP. ${ }^{18}$ A wide range of electrocardiographic abnormalities were recorded before, during, and after endoscopy, although there was no significant difference in the number of arrhythmias seen during these three periods (Table II). Most arrhythmias recorded were supraventricular and isolated ventricular extrasystoles, which are of little prognostic importance. There were significantly fewer patients with supraventricular extrasystoles when oxygen was given during gastroscopy $\left(\chi^{2}=5 \cdot 05\right.$; $0.01<\mathrm{p}<0.05)$. Their frequency, however, when present on an extrasystole per minute basis was similar both in the oxygen and air groups, and between the three monitored periods (Fig 2). Therefore this apparent reduction in their rate of occurrence is a reflection of the comparatively shorter period of monitoring during the procedure. Supraventricular extrasystoles occur with increasing frequency throughout life, but there is no evidence of an association with ischaemic heart disease or that their presence is of prognostic importance. ${ }^{27-29}$

There were no differences between the two groups for any sinister electrocardiographic abnormality, as defined earlier, when looked at either individually or in combination. In addition there was no correlation between the oxygen saturation and the frequency of supraventricular and ventricular extrasystoles. There was no demonstrable relation between medical history, smoking habits, age or sex and the development of arrhythmias or ST segment change in either group of patients.

This study has shown a larger proportion of electrocardiographic changes $(91 \%)$ than previous studies, ${ }^{+12}$ even though some of these included sinus tachycardia as an arrhythmia. This, defined as sinus rhythm with a rate of greater than 100 beats per minute, was present in many of our patients with or without oxygen and seems to be a normal physiological response. Many of the studies showing a low incidence of electrocardiographic abnormalities included cardiac monitoring only during the endoscopy procedure itself. In addition our study included only patients over 60 years, specifically to maximise the pick up of cardiac abnormalities. There was no evidence in this study that endoscopy induced electrocardiographic abnormalities, although to pick up significant numbers of serious arrhythmias the trial would have had to be considerably larger. Most of the electrocardiographic changes seen were clinically not important.

During this study oxygen saturation values did not fall below $86 \%$, which is at variance with some studies, ${ }^{16-1833}$ although in agreement with others. ${ }^{19036}$ Readings were taken only at one minute intervals, and therefore saturation values may have fallen lower in between, although the automatic alarm set at $85 \%$ was never activated. More importantly, other studies have used higher doses of benzodiazepine and also given opiates before treatment, which is likely to explain the lower oxygen saturation values. It is of interest that the postgastroscopy oxygen saturation values were significantly less than baseline even 60 minutes after the procedure. This would imply that if supplemental oxygen is given its administration ought to be extended into the postgastroscopy period.

As in previous studies there was a significant difference in the oxygen saturation values between the patients receiving oxygen and those given air, but we were unable to show any correlation between oxygen saturation and electrocardiographic abnormalities. In addition, there was no relation between cardiac arrhythmias or ST segment change and age, sex, shortness of breath or cardiac history. It was therefore not possible to predict, on the basis of patient characteristics, those who would develop cardiac arrhythmias.

The endoscopy committee of the British Society of Gastroenterology recently set out guidelines for monitoring patients during endoscopy, and included the recommendation that 'high risk' patients, a definition which included the elderly, should receive supplemental oxygen..$^{37}$ From our study, however, there was no evidence that supplemental oxygen led to any reduction of clinically important cardiac arrhythmias in patients over 60 . Our results do not, therefore, support the BSG guidelines that supplemental oxygen should be routinely used in the elderly. This study, however, excluded other 'high risk' patients, as defined in the BSG guidelines, such as those having emergency procedures, because the study was underway before their publication. We therefore cannot 
comment on the use of supplemental oxygen in these patients.

In conclusion electrocardiographic abnormalities are common in patients over 60 , but this study found no evidence that they are induced by gastroscopy. Supplemental oxygen increases oxygen saturation but does not reduce the incidence of clinically important cardiac arrhythmias or ST segment changes.

This work was presented to the British Society of Gastroenterology (Spring 1992) and has been published as an abstract (Gut 1992; 33 (suppl 1): S53).

We would like to thank Mrs Anne Liddell and the Endoscopy Unit staff at St Mary's Hospital, London for their assistance; and Unit staff at St Mary's Hospital, London for their assistance; and Dr Jane Wadsworth and Mr Luke Whittaker of the Academic
Unit of Public Health for the advice on the statistics. This project Unit of Public Health for the advice on the statistics. This project was funded by a
Health Authority.

1 Silvis SE, Nebel O, Rogers G, Sugawa C, Mandelstam P. Endoscopic complications: Results of the 1974 American Society of Gastrointestinal Endoscopy survey. FAMA 1976; 235: 928-30

2 Davis RE, Graham DY. Endoscopic complications: The Texas experience. Gastrointest Endosc 1979; 25: 146-9.

3 Daneshmend TK, Bell GD, Logan RFA. Sedation for upper gastrointestinal endoscopy: results of a nationwide survey. Gut 1991; 32: 12-5.

4 Schuman BM, Gale H. Electrocardiographic changes associated with gastroscopy. Bull Gastrointest Endosc 1962; 8: $10-3$.

5 DeMasi CJ, Akdamar K. Electrocardiography during upper gastrointestinal endoscopy. Gastrointest Endosc 1969; 16: $33-4$

6 McEwan-Alvardo G, Barnes RN, Wallace TI. Electrocardiographic response to upper gastrointestinal endoscopy. $A m \mathcal{F}$ Gastroenterol 1972; 57: 26-33.

7 Serebro HA, Coco AE, Tabatznik B. Continuous electrocardiographic monitoring employing the electrocardiocorder during gastrointestinal endoscopy. Gastrointest Endosc 1967; 14: 28-30.

8 Bough EW, Meyers M. Cardiovascular responses to upper gastrointestinal endoscopy. Am f Gastroenterol 1978; 69: 655-61.

9 Alam M, Schuman BM, Duvernay WF, Madrazo AC Continuous electrocardiographic monitoring during colonoscopy. Gastrointest Endosc 1976; 22: 203-6.

10 Pyorala K, Salmi HJ, Jussila J, Heikkila J. Electrocardiographic changes during gastroscopy. Endoscopy 1973; 5 186-93.

11 Fujita R, Kumura F. Arrhythmias and ischaemic changes of the heart induced by gastric endoscopic procedures. $A m \mathcal{F}$ Gastroenterol 1975; 64: 44-8.

12 Gupta SC, Gopalswamy N, Sarkar A, Suryaprasad AG Markert RJ. Cardiac arrhythmias and electrocardiographic changes during upper and lower gastrointestinal endoscopy. Milit Med 1990; 155: 9-11.

13 McAlpine JK, Martin BJ, Devine BL. Cardiac arrhythmia associated with upper gastrointestinal endoscopy in elderly associated with upper gastrointestina
subjects. Scott Med f 1990; 35: 102-4.

14 Levy N, Abinader E. Continuous electrocardiographic monitoring with Holter electrocardiography throughout all stages of gastroscopy. Dig Dis 1977; 22: 1091-6.

15 Mathew PK, Ona FV, Damevski K, Wallace WA Arrhythmias during upper gastrointestinal endoscopy. Angiology 1979; 30: 834-40.
16 Rostykus PS, McDonald GB, Albert RK. Upper intestinal endoscopy induces hypoxaemia in patients with obstructive pulmonary disease. Gastroenterology 1980; 78: 488-91.

17 Murray AW, Morran CG, Kenny GNC, MacFarlane P, Anderson JR. Examination of cardiorespiratory changes during upper gastrointestinal endoscopy. Anaesthesia 1991; 46: $181-4$.

18 Bell GD, Bown S, Morden A, Coady T, Logan RFA. Prevention of hypoxaemia during upper gastrointestinal Prevention of hypoxaemia during upper gastrointestinal endoscopy by mi: $1022-4$.

19 Griffin SM, Chung SCS, Leung JWC, Li AKC. Effect of intranasal oxygen on hypoxia and tachycardia during endoscopic cholangiopancreatography. BMF 1990; 300: 83-4.

20 Jones G. Oxygen saturation during upper gastrointestinal endoscopy. Br F Anaesth 1986; 58: 807P.

21 Hiss RG, Lamb LE. Electrocardiographic findings in 122043 individuals. Circulation 1962; 25: 947-52.

22 Chiang BN, Perlman LV, Ostrander LD. Relationship of premature systoles to coronary heart disease and sudden death in the Tecumseh epidemiologic study. Ann Intern Med 1969; 70: 565-70.

23 Brodsky M, Wu D, Denes P. Arrhythmias documented by 24 hour continuous electrocardiographic monitoring in 50 male medical students without apparent heart disease. $A m \mathcal{F}$ Cardiol 1977; 39: 390-4.

24 Kostis JB, McCrone K, Moreyra AE. Premature ventricular complexes in the absence of identifiable heart disease. Circulation 1981; 63: 1351-5.

25 Vismara LA, Pratt C, Price JE. Correlation of the standard electrocardiogram and continuous ambulatory monitoring in the detection of ventricular arrhythmias in coronary patients. $\mathcal{F}$ Electrocardiol 1977; 10: 299-303.

26 Lown B, Wolf $M$. Approaches to sudden death from coronary heart disease. Circulation 1971; 44: 130-41.

27 Clarke JM, Hamer J, Shelton JR, Taylor S, Venning GR. The rhythm of the normal human heart. Lancet 1976; i: 508-12.

28 Raftery EB, Cahman PMM. Long-term recording of the electrocardiogram in a normal population. Postgrad Med $\mathcal{F}$ 1976; 52 (suppl 7): 32-7.

29 Taylor IC, Stott RW. The significance of cardiac arrhythmias in the aged. Age Ageing 1983; 12: 21-8.

30 Pecora AA, Chiesa JC, Alloy AM, Santoro J, Lazarus B. The effect of upper gastrointestinal endoscopy on arterial oxygen tension in smokers and non-smokers with and withou premedication. Gastrointest Endosc 1984; 30: 284-8.

31 Whorwell PS, Smith CL, Foster KJ. Arterial blood gas tensions during upper gastrointestinal endoscopy. Gut 1976; 17: 797-800.

32 Rozen P, Fireman Z, Gilat T. The causes of hypoxaemia in elderly patients during endoscopy. Gastrointest Endosc 1982; 28: $243-6$

33 Bell GD, Reeve PA, Moshiri M, et al. Intravenous midazolam: A study of the degree of oxygen desaturation during upper gastrointestinal endoscopy. Br $\mathcal{F}$ Clin Pharmacol 1987; 23: 703-8.

34 Lavies NG, Creasy T, Harris K, Hanning CD. Arterial oxygen saturation during upper gastrointestinal endoscopy: influence of sedation and operator experience. $\mathrm{Am} \mathcal{F}$ Gastroenterol 1988; 83: 618-22.

35 Rimmer KP, Graham K, Whitelaw WA, Field SK. Mechanisms of hypoxaemia during panendoscopy. $\mathcal{f}$ Clin Gastroenterol 1989; 11: 17-22.

36 Kinoshita $\mathrm{Y}$, Ishido S, Nishiyama $\mathrm{K}$, Kitajima N, Itoh T, Inatome $\mathrm{T}$, et al. Arterial oxygen saturation, blood pressure, and pulse rate during upper gastrointestinal endoscopy influence of sedation and age. $\mathscr{J}$ Clin Gastroenterol 1991; 13: 656-60.

37 Bell GD, McCloy RF, Charlton JE, Campbell D, Dent NA, Gear MWL, et al. Recommendations for standards of sedation and patient monitoring during gastrointestinal endoscopy. Gut 1991; 32: 823-8. 